\title{
Causas del fracaso escolar en contextos de vulnerabilidad sociocultural desde la perspectiva docente
}

\section{Causes of school failure in contexts of sociocultural vulnerability from the teaching perspective}

DOI: http://dx.doi.org/10.17981/cultedusoc.12.1.2021.18

Recibido: 7 de julio de 2020. Aceptado: 01 de octubre de 2020. Publicado: 10 de febrero de 2021

Mariana Diez-Elola

Universidad de la República. Montevideo (Uruguay)

marianadiezx@gmail.com

Para citar este artículo:

Diez-Elola, M. (2021). Causas del fracaso escolar en contextos de vulnerabilidad sociocultural desde la perspectiva docente. Cultura, Educación y Sociedad, 12(1), 323-340. DOI: http://dx.doi.org/10.17981/cultedusoc.12.1.2021.21

\section{Resumen}

Latinoamérica se caracteriza por ser una región desigual, con altos niveles de exclusión social y desigualdad educativa. Desde este referente, el artículo sistematiza las hipótesis explicativas que elaboran los maestros sobre las causas de la estratificación en los resultados educativos. Se plantea un enfoque metodológico cualitativo, de carácter exploratorio, descriptivo e interpretativo, basado en el estudio de caso, a partir del cual, se estudian las representaciones sociales de los maestros sobre las causas del fracaso escolar, en una escuela de contexto sociocultural vulnerable en Montevideo (Uruguay). El fracaso escolar es entendido como el desempeño académico por debajo de lo esperado para el grado escolar que se cursa. Los resultados permiten reconstruir cuatro hipótesis explicativas que ubican las causas del fracaso escolar en: 1) la herencia genética, 2) la familia, 3) la institución educativa y 4) el contexto socioeconómico. Las explicaciones más prevalentes, fuertemente asociadas al ideal meritocrático y a una perspectiva medicalizadora de las dificultades escolares en contextos vulnerables, responsabilizan al niño o a su familia por el fracaso. Se concluye que es necesario considerar el impacto que el contexto social tiene en la determinación del problema del fracaso escolar.

Palabras clave: Desigualdad educativa; fracaso escolar; representaciones sociales

\section{Abstract}

Latin America is characterized by being an unequal region, with high levels of social exclusion and educational inequality. From this reference, the article systematizes the explanatory hypotheses elaborated by teachers about the causes of stratification in educational results. A qualitative methodological approach is proposed, of an exploratory, descriptive and interpretive nature, based on the case study, from which the social representations of teachers about the causes of school failure are studied, in a school with a vulnerable sociocultural context in Montevideo (Uruguay). School failure is understood as academic performance below expectations for the grade in school. The results allow us to reconstruct four explanatory hypotheses that locate the causes of school failure in: 1) genetic inheritance, 2) family, 3) educational institution and 4) socioeconomic context. The most prevalent explanations, strongly associated with the meritocratic ideal and a medicalizing perspective of school difficulties in vulnerable contexts, hold the child or his family for failure. It is concluded that it is necessary to consider the impact that the social context has in determining the problem of school failure.

Keywords: Educational inequality; school failure; social representations 


\section{INTRODUCCIÓN}

El artículo que se presenta expone algunas de las reflexiones producidas a partir de la investigación titulada "Representaciones sociales de los maestros sobre el fracaso escolar. Estudio de caso de una escuela de contexto sociocultural vulnerable del departamento de Montevideo, Uruguay", desarrollada en el contexto de la Maestría en Derechos de Infancia y Políticas Públicas de la Universidad de la República, Uruguay. El tema de interés se enmarca en el área de las políticas públicas en el ámbito educativo, abordando la perspectiva docente en relación a la estratificación de los resultados educativos, y más específicamente las explicaciones causales que estos elaboran sobre el fracaso escolar.

A efectos de contextualizar la temática se considera importante señalar que Latinoamérica se caracteriza por ser una región profundamente desigual, resultado de la distribución heterogénea del capital material y simbólico entre sus habitantes (López-Calva y Lustig, 2010, López, 2005). Este fenómeno genera altos niveles de fragmentación y exclusión social, situación que precede el ingreso al sistema educativo y condiciona claramente el tránsito escolar. En los últimos años, Uruguay ha realizado importantes esfuerzos en el campo de la inclusión educativa a través de la instalación de la temática en la agenda pública y de la sanción de leyes al respecto. En junio de 2008 se remite al parlamento nacional el Proyecto de Ley 18.437 (Ley General de Educación, 2008), en el que se reconoce explícitamente el derecho a la educación como un bien público y social.

$\mathrm{El}$ artículo primero establece que: "El Estado garantizará y promoverá una educación de calidad para todos sus habitantes, a lo largo de toda la vida, facilitando la continuidad educativa" (Ley 18.437, 2008). En este sentido, se han implementado políticas educativas tendentes a garantizar el acceso universal y la expansión del sistema — sobre la base de la obligatoriedad y la gratuidad-, iniciativas que permitieron un aumento sustancial de la cobertura y la matriculación, y el ingreso de sectores de la sociedad antes excluidos, para romper así, con la homogeneidad que en términos de nivel socioeconómico y procedencia cultural, caracterizaba a los estudiantes. En este contexto, se hace necesario sumar a la discusión la consideración de al menos dos aspectos que tensionan el potencial democratizador de los avances antes mencionados y obstaculizan el goce efectivo del derecho a la educación para determinados sectores de la sociedad.

En primer lugar, el acceso a la educación a través de la universalización es una condición necesaria pero no suficiente para garantizar el ejercicio pleno de este derecho humano fundamental. Las condiciones concretas de existencia de ciertos grupos sociales determinan circunstancias de arribo al sistema educativo desventajosas, realidad que no debe ser ignorada, en tanto se vincula claramente con las trayectorias educativas y con las posibilidades de éxito o fracaso escolar (Castorina y Kaplan, 1997). En la actualidad, se advierte una tendencia a circunscribir la comprensión del fracaso escolar únicamente al plano individual. Sin embargo, este enfoque ha demostrado ser empíricamente ineficiente, en tanto las respuestas que se ensayan desde esta perspectiva, no logran una transformación franca de las herramientas necesarias para el aprendizaje, pues el contexto de vulneración que sostiene su construcción, persiste. Esta afirmación se apoya en los siguientes datos: 
- Si bien se registra una disminución sostenida de la incidencia de la pobreza para hogares del país, su concentración prevalece en la infancia. Si se considera únicamente a Montevideo la situación empeora, ya que es el departamento del país con mayor incidencia de este indicador (Instituto Nacional de Estadística, 2018).

- Según la Organización de Naciones Unidas (ONU, 2017), en Uruguay, el fracaso y la deserción escolar se concentran en la infancia en situación de pobreza.

- De acuerdo con la Administración Nacional de Educación Pública (ANEP, 2019) en contextos socioculturales desfavorables, se constata que la repetición, uno de las formas en las que se materializa el fracaso escolar, se concentra preponderantemente en los primeros grados escolares, particularmente, en primer grado. Esta situación contribuye fuertemente a la desafiliación escolar en etapas posteriores del ciclo educativo.

En segundo lugar, la fragmentación que caracteriza al sistema educativo uruguayo determina oportunidades heterogéneas a los niños y adolescentes que por el transitan, generando circuitos educativos diferenciados en función del nivel socioeconómico de los alumnos y del lugar de residencia, situación que contribuye a la cristalización del proceso de exclusión. Tomando en cuenta los aspectos antes señalados, resulta fundamental el diseño de políticas públicas tendientes a garantizar tanto el acceso a la educación en condiciones de igualdad, como una transformación del sistema educativo que permita generar los escenarios adecuados para que todos los alumnos desarrollen su potencial.

El avance hacia la efectiva consolidación de estos cambios resulta aún, insuficiente. Este proceso se ha caracterizado por un marcado desencuentro entre, por un lado el diseño de políticas educativas y por otro, lo que ocurre cotidianamente en las instituciones escolares, claramente asociado a las concepciones, sentidos y expectativas que construyen los docentes en relación a su tarea, los alumnos, la escuela y sus funciones. Así, existe una brecha que parece insalvable entre los discursos teóricos que abogan por la inclusión, entendida en sentido amplio, y las prácticas escolares habituales, particularmente en las instituciones que atienden a los sectores sociales en situación de mayor vulnerabilidad (Garnique-Castro y Gutiérrez-Vidrio, 2012).

Se considera que las representaciones sociales (Moscovici, 1979) elaboradas por los docentes respecto de las causas del fracaso escolar son relevantes en tanto condicionan las prácticas y la interacción entre maestros y estudiantes. En el contexto de la institución educativa, estas elaboraciones sociales pueden actuar como límite o como oportunidad, y "adquieren una eficacia simbólica especifica en relación a las desigualdades en los destinos y en los logros de los niños provenientes de las diferentes clases sociales" (Kaplan, 2013, p. 9).

Se estimó necesario elaborar una definición respecto de lo que en el contexto de este trabajo se entiende por fracaso escolar, por cuanto las conceptualizaciones identificadas habitualmente pueden no coincidir con la presente propuesta. De esta manera, el fracaso escolar es concebido como un significante general que engloba una visión respecto del rendimiento académico de los estudiantes, objetivable en cuestiones concretas como la 
repetición, la extraedad, las calificaciones escolares bajas, el desfasaje importante respecto del nivel de conocimientos esperados para determinado grado escolar, el ausentismo y la desafiliación educativa, y que compone además, un sentido social.

En la literatura consultada el fracaso escolar, ha sido definido por diferentes autores de diversas maneras, por lo que es posible caracterizarlo como un concepto polisémico, sobre el que es difícil encontrar opiniones unívocas. En líneas generales, puede ser entendido como el desempeño por debajo de lo esperado en el ámbito escolar; el ausentismo, la asistencia intermitente, el bajo rendimiento, la repetición, la extraedad, la desafiliación educativa, son algunas de las formas en las que se expresa. También implica logros diferenciados según el sector social al que pertenece el alumno. Frecuentemente, se observa la combinación de varias de las situaciones antes mencionadas, a las que eventualmente se pueden agregar dificultades conductuales (Kachinovsky y Gabbiani, 2014; Escudero, 2005; Marchesi y Pérez, 2003).

El trabajo de investigación que aquí se presenta estudia las representaciones sociales que elaboran los docentes de una escuela de contexto sociocultural vulnerable respecto de las causas del fracaso escolar. Se plantean además, algunas reflexiones a partir de los resultados a los que se arribó. De esta manera, se pretende colaborar en la comprensión de los supuestos que guían el trabajo cotidiano en las aulas y acercarse al análisis del complejo escenario del tratamiento de las diferencias en el ámbito escolar a la luz de estos elementos, lo que en última instancia, puede favorecer un cambio en la mirada de los docentes sobre esta problemática a partir de un posicionamiento crítico.

\section{Metodología}

El diseño metodológico propuesto responde principalmente al enfoque procesual para el estudio de las representaciones sociales, caracterizado por concebir a la persona como productora de sentidos en un contexto socio-histórico y cultural específico (Banchs, 2000). Este enfoque indaga el contenido de las representaciones sociales a partir de un acercamiento de tipo cualitativo, en este caso, exploratorio, descriptivo e interpretativo, que orienta la atención del investigador hacia el contexto y el discurso de los actores sociales, e intenta acercarse al significado que la realidad tiene para estos, y a la manera en que estos significados se enlazan con sus acciones y pensamientos (Sandoval, 2002). Así, este enfoque permitió recuperar la voz y la perspectiva de los actores educativos respecto de las causas del fracaso escolar.

Se planteó un enfoque metodológico basado en el estudio de caso de tipo interpretativo (Yin, 2009), a partir del cual los datos obtenidos se utilizan para explicar los supuestos teóricos que sostienen la investigación (Pérez, 1994). En relación a estos supuestos se plantea que los docentes construyen representaciones sociales que explican las causas del fracaso escolar principalmente a partir de características propias del niño o de su entorno familiar próximo. La jerarquización de estos aspectos termina por cristalizar una visión reduccionista del problema en la que se desconocen las condiciones estructurales generadas por la desigualdad social, que condicionan fuertemente el tránsito por la institución escolar y la construcción de las herramientas que sostienen los aprendizajes. Estas construcciones, que operan desde la dimensión inconsciente de la subjetividad, transforman las diferencias 
sociales en innatas y actúan como anticipaciones taxativas. A partir de este movimiento, se legitima y naturaliza la marcada estratificación de los resultados escolares en función del nivel socioeconómico del estudiante.

El enfoque metodológico seleccionado permitió acercarse a la comprensión de procesos internos, que pueden quedar invisibilizados por la cotidianeidad. La lógica de la sistematización procedimental implica elaborar el problema de investigación, precisar el objeto de estudio, construir un marco de referencia y seleccionar un enfoque metodológico adecuado. El problema de investigación que aquí se propone refiere a las representaciones sociales que portan los docentes que desarrollan su tarea en una escuela pública común de contexto sociocultural vulnerable del departamento de Montevideo, respecto de las acusas del fracaso escolar. El estudio se interesa por las perspectivas y valoraciones de los maestros en relación a este tema.

El objeto de estudio sobre representaciones sociales reúne tres elementos: el sujeto que construye la representación social, el contexto particular en el que surge esta representación y el objeto a representar (Cuevas, 2016). Uno de los rasgos distintivos de la representación social es que el sujeto que la elabora es un sujeto social, es decir pertenece a un grupo, una comunidad organizada, en el seno de la cual establece interacciones regulares con los demás integrantes, compartiendo una trayectoria histórica, un lenguaje y una cultura particulares. Las representaciones subjetivas de los docentes se elaboran bajo el influjo de determinantes sociales e históricos generales, y no solo en correspondencia con los determinantes propios del ámbito escolar, aunque este último les imprime una tónica particular.

De esta manera, el sujeto que elabora la representación social y el contexto particular en el que emerge dicha representación quedan definidos de la siguiente manera. En función del propósito de la investigación, se seleccionó una escuela pública de educación común, perteneciente al quintil $1^{1}$, que agrupa las escuelas a las que concurren los niños en situación de mayor vulnerabilidad sociocultural. El campo empírico quedó constituido por todos los maestros que desarrollaban su actividad profesional en dicho centro. Sumado a esto, la escuela seleccionada presenta indicadores de repetición, asistencia insuficiente y abandono intermitente por encima de la media nacional. Además de las maestras de grado, el centro educativo seleccionado contaba con maestra de apoyo y maestras comunitarias, lo que permitió recuperar los discursos asociados a distintos roles y trayectorias docentes, y contrastar la opinión de diferentes actores educativos de la escuela, cada uno desde su función diferenciada.

El tercer elemento, el objeto de la representación social (algo o alguien), debe ser relevante para los sujetos y estar presente de manera recurrente en su cotidianidad, asociado a sus prácticas frecuentes. Al captar la atención de los actores sociales, el objeto a ser representado, provoca intercambios y debates que se orientan a explicar e interpretar la situación problemática que se le presenta al grupo (Jodelet, 2011). Para el caso de este trabajo el objeto de la representación son las causas del fracaso escolar.

\footnotetext{
${ }^{1}$ En el Sistema educativo uruguayo, el nivel de contexto sociocultural de las escuelas se construye dividendo el total de escuelas públicas en 5 grupos de igual cantidad: el quintil 1 agrupa al $20 \%$ de las escuelas de contexto más vulnerable y el quintil 5 al $20 \%$ de las de
} contexto menos vulnerable. 
A partir del diseño metodológico propuesto y a efectos de garantizar la credibilidad de los datos se apeló a diferentes estrategias. En primer lugar, la elección de la escuela se realizó tomando en consideración los elementos contextuales que, de acuerdo con la bibliografía consultada, mayor peso tienen sobre el fracaso escolar, específicamente el nivel de contexto sociocultural de la escuela (Kachinovsky y Gabbiani, 2014). En segundo lugar, se utilizó la triangulación de las técnicas seleccionadas para realizar la investigación: la entrevista semiestructurada y el análisis de documentos. La triangulación permitió incrementar los criterios de validez y confiabilidad, y acercarse a una visión globalizada del tema de investigación en un contexto específico, ofreciendo interpretaciones matizadas de las experiencias de los participantes (Wood y Smith, 2018).

En esta investigación, se optó por realizar una entrevista de tipo semiestructurada, ya que esta modalidad resulta lo suficientemente flexible en cuanto a la secuencia en la que se presentan las preguntas relacionadas con el objeto de estudio. De acuerdo con este formato de entrevista, el orden de las preguntas puede ser revisado y ajustado en el devenir del encuentro con el entrevistado, a efectos de facilitar el intercambio, el aporte de la información o, eventualmente, su ampliación (Wood y Smith, 2018). También, el bajo grado de estructuración del tipo de entrevista seleccionado, habilita al entrevistado a exponer su discurso desde su propia lógica.

El guión de la entrevista se elaboró en función de ejes de análisis que permitieron recuperar aspectos relevantes de las representaciones sociales. La entrevista se organizó teniendo en cuenta dimensiones que responden a la teoría de las representaciones sociales: información, representación y actitud (Moscovici, 1979). Se agregó un cuarto eje con el objetivo de dar cuenta de las condiciones concretas en las que se elaboran estas representaciones, por entender que es a partir del inter-juego de aspectos de orden personal, social, institucional e histórico que estos constructos adquieren su estatus. Así, esta dimensión, indaga los elementos más significativos que median la construcción de la representación desde el punto de vista de la persona (formación profesional, antigüedad laboral, etc.).

Los datos obtenidos en el contexto de las entrevistas fueron tratados a partir de un análisis de contenido, tomando en cuenta los grandes ejes temáticos sobre los que versan las preguntas realizadas y aquellos temas que surgieron de manera espontánea a instancias de los entrevistados. Para esto se definieron las unidades de análisis, se codificó la información y se establecieron categorías de análisis (Cáceres, 2003). Se prestó especial atención a los acentos y matices con los que las maestras abordaron las distintas temáticas. En todos los casos interesó sistematizar los sentidos discursivos que se construyen y emergen en contextos de vulnerabilidad respecto del fracaso escolar, e interpretar la incidencia potencial de estas representaciones sobre las prácticas educativas concretas, las trayectorias académicas y los resultados escolares desiguales.

La información obtenida a través de una técnica — entrevista semiestructurada—, se cotejó con otra — análisis documental—, combinando, a lo largo del estudio, fuentes de datos primarias y secundarias. Se realizaron trece entrevistas y se analizó la información secundaria proveniente de los documentos sistematizados de las Asambleas Técnico Docentes (ATD) del Consejo de Educación Inicial y Primaria, desde el año 2006 al 2018. 
La totalidad de las maestras accedieron a que la entrevista se grabe y durante la misma se tomaron registros escritos complementarios. Posteriormente se realizó una transcripción exacta del material. Los documentos de las ATD son de acceso público y se encuentran disponibles en línea.

En relación a las características de la muestra es importante señalar que la totalidad de las docentes (13) son de sexo femenino, observándose sí heterogeneidad en cuanto a: edad, antigüedad en la docencia, cantidad de años en la institución en la que se desarrolló el estudio, características del cargo que ocupan. Respecto de este último punto la muestra está conformada por: 10 maestras de grado, 2 maestras comunitarias, 1 maestra de apoyo; además, de las 13 maestras 8 ejercen su cargo de manera efectiva y 5 lo hacen en forma interina.

\section{RESUltados Y DISCUSIÓN}

En este apartado se analizan las explicaciones causales que las docentes de una escuela de contexto sociocultural vulnerable del departamento de Montevideo, construyen respecto del fracaso escolar. La caracterización que aquí se presenta se basó en la consideración de aquellos elementos que aparecían con mayor insistencia en el discurso. Así, se lograron identificar cuatro hipótesis explicativas en función del énfasis asignado en el discurso a las siguientes variables:

- La herencia genética.

- La familia.

- La institución educativa.

- El contexto socioeconómico.

Cabe señalar que la mayoría de las líneas argumentales se ubicaron en las dos primeras variables: herencia genética y familia, y que no se observaron asociaciones claramente significativas entre las distintas variables que caracterizan a la muestra (antigüedad en el ejercicio de la función docente, formación, rol desempeñado en la institución educativa, edad, etc.). A continuación, se desarrollan cada una de las hipótesis.

\section{Explicaciones causales centradas en el niño}

La hipótesis más prevalente en los discursos analizados, enmarcada en una perspectiva atravesada por el determinismo biológico, explica las posibilidades de éxito o de fracaso escolar en términos de capacidades innatas para el aprendizaje. Específicamente, el fracaso se concibe desde un modelo patológico individual, cobrando especial relevancia en estos discursos el argumento de la herencia genética como explicación determinante de los malos resultados educativos. Así, la trama argumentativa ubica la causa del fracaso escolar en la persona, específicamente en la dimensión biológica del desarrollo, y dentro de esta en aspectos innatos y heredados. No se consideran otras dimensiones que vertebran el proceso de desarrollo como por ejemplo la social. 
Dentro de la dimensión biológica se reporta, en varias de las entrevistas analizadas, la idea de una inteligencia que afirman se encuentra por debajo de lo normal, es decir un supuesto déficit cognitivo como explicación del fracaso escolar. No se pretende en este trabajo negar las diferencias de tipo intelectual que existen entre las personas. Lo que interesa poner en discusión aquí son las conceptualizaciones reduccionistas de inteligencia que desconocen el impacto que el medio social tiene en su desarrollo. Se considera importante interpelar las condiciones en las que la inteligencia, apoyada en instrumentos cognitivos diversos y complejos, se construye, problematización que no aparece en el discurso de las docentes que explican la estratificación de los resultados escolares desde aspectos innatos del niño.

Piaget (1999), referente en la materia, observaba que la constancia en el orden con el que se suceden las fases del desarrollo intelectual depende de la maduración del sistema nervioso. Sin embargo, las variaciones en la edad de aparición, y eventualmente, la no aparición de las últimas fases, evidencian que la maduración no es el único factor interviniente: el medio social tiene un fuerte impacto en el desarrollo intelectual.

Estas concepciones reduccionistas de la inteligencia la entienden como una propiedad heredable que permanece invariable, o con escasas modificaciones, a lo largo de la vida. Desde esta perspectiva las maestras le atribuyen a la escuela y a su accionar concreto, un impacto en extremo limitado en la vida de los niños.

Lewontin, Steven y Kamin (2003) sintetizan una serie de estudios que señalan que no es posible medir exactamente qué porcentaje de la inteligencia se hereda, ni determinar en forma absoluta las características y posibilidades de las personas a partir de los genes. Aun así, y en virtud de los temas abordados en este trabajo, la cuestión de la herencia de la inteligencia resulta secundaria, en tanto que se herede no significa, de manera alguna, que permanezca invariable a lo largo de la vida. Al respecto, la genética evolutiva plantea que en todo momento el ser humano es la síntesis no lineal de la interacción entre la dotación genética y el entorno.

[...] una comprensión plena de la condición humana exige una integración de lo biológico y de lo social en la que ninguno obtenga primacía o prioridad ontológica sobre el otro, sino en la que se les considere esferas relacionadas de modo dialéctico, un modo que distinga epistemológicamente entre niveles de explicación referidos al individuo y niveles relativos a lo social, sin que se aplasten mutuamente o se niegue la existencia de alguno de ellos (Lewontin et al., 2003, p. 96).

Se evidenció, además, que las expectativas acotadas expresadas por las docentes respecto de las posibilidades de los niños con los que trabajan, se asocian, al menos a nivel del discurso, en propuestas educativas menos desafiantes en comparación con las que se desarrollan con alumnos provenientes de contextos socioculturales que les ofrecen más y mejores oportunidades.

En este sentido se consideran relevantes los aportes realizados por Gould (2003), al discutir el uso que las perspectivas basadas en el determinismo biológico realizan de la "inteligencia", —entendiéndola como una cualidad natural, unitaria y lineal—, para legitimar las desigualdades sociales y educativas. El autor mencionado advierte sobre los efectos que a lo largo de la historia ha tenido el resurgimiento de estas ideas, señalando 
particularmente el recorte en los gastos que el Estado dispone para programas sociales o educativos, bajo el falaz argumento que considera inútil realizar inversiones en poblaciones deficitarias que naturalmente están destinadas al fracaso.

Así, la mirada que construyen estas docentes sobre el fracaso escolar, se alinea con un proceso medicalizador (Affonso, Collares y Untoiglich, 2013) de las dificultades escolares en contextos vulnerables, a partir del cual problemas que son de orden social y político, se abordan como problemas individuales, atribuyendo su causa principalmente, a determinantes biológicos. En el caso de la población con la que trabajan, señalan una capacidad innata limitada para los aprendizajes, justificando el fracaso escolar, y posteriormente el social, como destinos casi inexorables. De esta manera, la desigualdad social se entiende a partir de la constatación de diferencias interindividuales, como si esta desigualdad fuera inherente a la persona y por ende expresión de la diversidad de la naturaleza humana.

Algunas de las docentes entrevistadas señalaron enfáticamente que las trayectorias educativas no dependen de manera alguna de la institución escolar. Desde esta perspectiva, la escuela se comporta como un aparato neutro que trata a todos sus alumnos por igual, ofreciendo iguales oportunidades, y por lo tanto la diferencia en los resultados solo puede ser adjudicada a las personas, quedando el sistema exento de cualquier responsabilidad.

Esta forma de representarse las causas del fracaso escolar tiene efectos en las prácticas educativas cotidianas de las docentes. En este sentido, se reconocieron a nivel del discurso, una serie de demandas persistentes, que se entiende son consecuencia directa de la manera particular en la que se concibe y explica el fracaso escolar. Entre estas demandas destacan: la creación de equipos técnicos, la realización de evaluaciones y diagnósticos — casi exclusivamente de los aspectos intelectuales- y la derivación a escuela especial. Aun así, estas alternativas son consideradas como dispositivos paliativos orientados a enfrentar una situación que entienden desborda sus posibilidades y las de la escuela.

En definitiva, el énfasis en factores propios del niño como explicación del fracaso escolar, desconoce la importancia del entorno en la construcción de las herramientas que sostienen los aprendizajes, dejando escaso margen para la consideración de las circunstancias concretas de existencia, es decir las condiciones en las que las personas nacen y se desarrollan. En los discursos representativos de esta hipótesis, se observa con insistencia la conversión de aspectos que en realidad son construidos socialmente, incorporados, — por ejemplo, las herramientas para el aprendizaje-, en propiedades heredadas genéticamente y estáticas, lo que termina por justificar un "estado de las cosas", en este caso un orden social desigual.

\section{Explicaciones causales centradas en el contexto familiar}

La segunda hipótesis más prevalente de la investigación, emparentada con la perspectiva antes expuesta, ubica en el contexto familiar los fundamentos del fracaso escolar. De acuerdo con algunos de los planteamientos, la dimensión familiar opera como una instancia que refuerza, en la mayoría de los casos, las dificultades innatas, observándose 
una marcada tendencia a explicar el fracaso escolar, por la historia de fracasos transgeneracionales de las familias. La escuela como institución, y especialmente las condiciones generadoras de desigualdad, continúan sin ser cuestionadas.

$\mathrm{Al}$ igual que en los argumentos que depositan en aspectos intelectuales la causa del fracaso escolar, aparece la mención a la inteligencia. Se utiliza con frecuencia el término "brillante" en referencia a los niños que provienen de familias percibidas como adecuadas y correlacionadas positivamente a las posibilidades de éxito escolar. Estas familias son señaladas como excepciones en el contexto de la institución educativa en la que se desarrolló la investigación. En contraposición, algunas de las expresiones que se utilizan en referencia los niños que consideran con un nivel intelectual inferior son: "No les da la cabeza", "no les entra nada", "tienen un nivel inferior", entre otros.

Así, la lógica que se instala es la de responsabilizar, casi de manera exclusiva, a los padres por los desempeños académicos de los niños, sean estos adecuados o deficitarios, omitiendo la pregunta por las condiciones de vida estructurales. Tal como lo señala López (2010) en su trabajo, en los discursos de las entrevistadas se va delineando una perspectiva que entiende que los padres no cumplen de manera adecuada su función de apoyo y sostén, y de esta manera explican el fracaso escolar.

De manera complementaria, en algunas de las entrevistas se señala que si la familia y el niño se esfuerzan lo suficiente podrán sobreponerse, aunque en forma acotada, a las adversidades asociadas al contexto socioeconómico en el que están. En consecuencia, en estos discursos el fracaso es entendido como el corolario de un nivel intelectual descendido, y/o de un esfuerzo - individual o familiar - que no llega a ser suficiente, y que de manera frecuente se presenta como una elección de las personas es decir, las familias optan por esforzarse o no. Esta perspectiva le asigna a la pobreza un origen casi voluntario, con lo cual se refuerza la idea de una responsabilidad individual sobre el desempeño escolar.

El discurso parece traducir también que el esfuerzo es una cualidad de menor valor, en tanto aprendida, mientras que la inteligencia, concebida como una propiedad que se hereda genéticamente, goza de un prestigio mayor. El esfuerzo se presenta frecuentemente mencionado como un atributo que deben poseer las familias pobres si pretenden mejorar su lugar en la sociedad: el individuo pobre debe estar dispuesto a realizar determinados sacrificios y a esforzarse más que los individuos pertenecientes a las clases sociales mejor posicionadas, y este esfuerzo debe trascender el ámbito educativo. En la narrativa de algunas de las docentes el esfuerzo y el sacrificio se conciben como una suerte de marcas que acompañan, o más bien que debieran acompañar, la existencia de los niños pobres.

Se identifica con fuerza la vigencia de un discurso que enfatiza el mérito como forma de trascender la situación social desventajosa, prevaleciendo por tanto, la explicación individual del fracaso y del éxito educativo. En cualquier caso, la responsabilidad ulterior por la trayectoria educativa recae en la persona o en el núcleo familiar, de quien se espera que pueda construirse de manera escindida del contexto en el que se desarrolla, o que en todo caso se sobreponga a éste a partir de su esfuerzo. No aparece en estos discursos una lectura del problema del fracaso escolar en términos de derechos vulnerados u oportunidades negadas a las familias de los niños y adolescentes con los que trabajan. 
Así, la jerarquización de aspectos externos a la institución escolar y construidos -imaginariamente- como independientes del contexto, termina por cristalizar una visión reduccionista del problema que desconoce las condiciones estructurales generadas por la desigualdad social y naturaliza los malos resultados académicos que obtienen determinados sectores de la sociedad. Así, esta desigualdad social, presente desde antes del ingreso al sistema educativo, se expone a nivel discursivo como una diferencia natural, y por ende inevitable.

\section{Explicaciones causales centradas en la institución escolar}

Los discursos ubicados en esta tercera hipótesis interpelan de manera matizada la dimensión institucional, como generadora o como potenciadora de la desigualdad educativa. En todos los casos, los planteos se realizaron en el contexto de discursos que no dejaron de lado la consideración de las aptitudes personales y del contexto familiar, como explicaciones de la estratificación en los logros escolares.

Así, desde esta perspectiva, minoritaria en el contexto de la investigación, aparece cierto cuestionamiento al formato que la escuela oferta, particularmente en lo que respecta a la concepción homogénea del alumnado, y en este sentido, algunas entrevistadas subrayan la necesidad de pensar formatos alternativos que contemplen la diversidad de los estudiantes en términos de intereses y posibilidades. Esta idea también queda expresada en los documentos que sintetizan la ATD (2012):

El formato escolar es una situación de emergencia en muchas escuelas por el fracaso escolar.

[...] El modelo de escuela homogénea tradicional, naturalizado como la única escuela posible, no alcanza para cumplir los fines de educación e inclusión socio-educativa en la actualidad (p. 27).

Esta cita traduce cierta preocupación por implementar dispositivos o estrategias que permitan mejorar las condiciones de tránsito por el sistema educativo; a decir de Rodelo y Castro (2016), los fines del sistema educativo deben orientarse en mayor grado al desarrollo humano de los actores participantes.

Por otro lado, y asociado a estos planteamientos algunas maestras, señalan la necesidad de establecer un vínculo fluido entre la institución escolar y la familia. En varias de las entrevistas realizadas existe una referencia frecuente al vínculo entre la escuela y la familia, en términos negativos, conflictivos. Al respecto, Bourdieu (2005) señala que la relación entre las familias provenientes de los sectores populares y la escuela se ve obstaculizada por las diferencias culturales. Los valores, discursos y prácticas que predominan en la institución educativa son propios de las clases medias de la sociedad, y en este sentido, se privilegian códigos que no son cercanos a otros estratos sociales. Cabe señalar además que la escuela es para muchas familias la gran ordenadora de la vida familiar, al aportar cierta regularidad de propuestas, días y horarios escolares.

Las opiniones que asocian el fracaso escolar con la oferta educativa, parecen insinuar que si se modificaran las propuestas y las acciones de los actores escolares, el problema podría, eventualmente, revertirse, ya que se lograrían compensar, al menos en parte, las marcadas desigualdades con las que niños provenientes de diferentes estratos socioeconómicos, ingresan al sistema educativo. Respecto de este último punto resulta importante 
subrayar que la distribución inequitativa del capital económico y cultural en Latinoamérica determina un orden social caracterizado por ser desigual e injusto (Serrano y Benzaquén, 2017). La desigualdad es anterior al ingreso escolar, y en este sentido, el peso de las condiciones de arribo a la institución educativa no puede ser negado o subestimado, en tanto se vincula fuertemente con las posibilidades de éxito o de fracaso. Aun así, y sin desestimar las condiciones estructurales generadores de desigualdad social, es posible reconocer la existencia de algunos mecanismos que se producen y/o reproducen dentro de los muros de la propia escuela, que se entiende pueden contribuir a generar la desigualdad en los resultados escolares.

Así, la perspectiva presentada en este apartado interpela el sistema educativo de manera matizada; el hecho de que al legitimar la cultura dominante, la institución escolar no pueda más que reflejar, en el mejor de los casos, un orden social arbitrario e injusto, sigue quedando fuera del análisis. La tensión que parece subyacer a esta hipótesis refiere a la consideración de la escuela como una institución que tiende a verificar y/o a amplificar las diferencias sociales, o como una institución que puede desafiar el orden social imperante (Martinis y Falkin, 2017).

\section{Explicaciones causales centradas en el contexto social}

La última hipótesis, que contribuye a la dispersión en el discurso de las maestras respecto de las causas del fracaso escolar, reúne aquellas opiniones y creencias docentes que explican la desigualdad a nivel de los logros académicos por las condiciones de existencia desventajosas que impone el contexto socioeconómico a determinados sectores de la sociedad. Se señala que esta fue la explicación con menor grado de representatividad a nivel de los discursos de las maestras, ya que en general las entrevistadas ubicaron esta variable como consecuencia y no como causa de los resultados desiguales en diferentes ámbitos de la vida. Así, en términos generales, la situación de vulnerabilidad en la que viven muchas de las familias de los niños que concurren a este centro educativo, es percibida como el resultado de su falta de capacidad y/o de empeño para revertirla.

Las opiniones agrupadas en esta hipótesis enmarcan la situación de los alumnos de escuelas de contexto sociocultural vulnerable, en un proceso social más amplio que precede al ingreso al sistema educativo y que lo condiciona. También, se advierte cierto cuestionamiento a los actos de nominación de los niños que transitan por estas escuelas y al desarrollo de prácticas inclusivas, al menos a la forma en la que estas prácticas se desarrollan actualmente. Se considera que esta reflexión puede asociarse a ciertos discursos que soslayan los efectos de la desigualdad social, y nominan como diverso aquello que en esencia es desigual. Se desplazan así, las verdaderas causas de las dificultades que presentan algunos grupos de la sociedad para su escolarización, desde un orden social injusto en el que se vulneran derechos y que impone condiciones desventajosas para el desarrollo de las personas, a entender la pobreza como una característica que se presenta como intrínseca al individuo. Un ejemplo de esto lo constituye la cada vez más frecuente, asimilación de la pobreza a la diversidad. La siguiente cita ilustra lo expuesto: 
Con renovadas operaciones discursivas y prácticas discriminatorias, la ideología meritocrática se ve reforzada a través de mecanismos cada vez más refinados, más sutilmente eufemizados. [...] Estoy pensando en cómo a la cualidad de "pobre" se la connota como atributo de "diversidad", para dar un caso que es cada vez más evidente; esto es, las notas características de la "cultura de la pobreza" se transmutan en cualidades intrínsecas de la persona o grupo (Kaplan, 2005, p. 78).

En esta línea, se presenta la perspectiva de la ATD (2011), que refleja un posicionamiento claro respecto de este tema:

Hay por lo menos dos acepciones del concepto de inclusión educativa: uno remite a la inclusión de niños con diversas discapacidades, en instituciones de educación común. El otro se refiere a la inclusión educativa de niños pertenecientes a contextos de pobreza. En muchas ocasiones el discurso se presenta indiferenciado, lo que genera por un lado la confusión de las diferentes situaciones y por otro lado naturaliza la exclusión social como hecho inevitable y no producto de las condiciones sociales existentes (ATD, 2011, p. 50).

La pobreza y la exclusión no forman parte de la diversidad de la naturaleza humana, en tanto son construcciones sociales que dependen de los contextos históricos, y no características inherentes a las personas.

A modo de cierre del análisis realizado sobre las explicaciones causales elaboradas por las docentes con relación a las causas del fracaso escolar se señala que en términos generales, la desigualdad educativa es percibida por las entrevistadas como inevitable, aparece naturalizada en sus discursos. Los argumentos más prevalentes refieren a las diferencias interindividuales, específicamente aquellas de carácter genético. Estas diferencias explicarían una aptitud innata y un grado de inteligencia superior que justifican el buen desempeño académico alcanzado por algunos estudiantes. El resto de los alumnos, - la mayoría, desde el punto de vista de las maestras entrevistadas-, fracasan a causa de su propia naturaleza, de una condición intrínseca, o de un esfuerzo personal y/o familiar valorado como insuficiente. Son estas aptitudes personales las que, en última instancia, separan a los niños exitosos en el ámbito educativo de aquellos que fracasan.

Detrás de tales afirmaciones subyace la idea del mérito propio y del esfuerzo familiar, como únicas variables que se discuten respecto del problema de las causas del fracaso escolar, es decir los logros son siempre individuales y no dependen del entorno social y cultural del que proviene el estudiante. El ideal meritocrático, permea el discurso de las entrevistadas y retorna sobre los alumnos y sus familias, especialmente en los contextos de vulnerabilidad social en los que trabajan, exigiendo un esfuerzo que los haga merecedores del ascenso social (Ochoa y Orbeta, 2017).

Así, dentro de esta narrativa el esfuerzo se plantea como un elemento fundamental asociado al éxito y al buen tránsito por la institución escolar, esto es: basta con el esfuerzo personal para tener éxito. Las docentes se mostraron muy críticas respecto de aquellas familias y estudiantes que, desde su punto de vista, no se esfuerzan tanto como debieran; el esfuerzo se piensa como efecto exclusivo de la voluntad del estudiante, que puede elegir o no obtener buenos resultados académicos. Este es el discurso donde el ideal meritocrático aparece con más fuerza y cobra un lugar relevante en las argumentaciones (Kreimer, 
2001). Asociada a estas creencias, se identificó también la idea de que el sistema educativo ofrece las mismas oportunidades a todos los niños. Asimismo, no emerge en los discursos analizados una referencia clara al papel que el Estado debe desempeñar como garante de derechos (Santos, 2019).

La mayoría de las docentes entrevistadas entienden que la desigualdad educativa se explica por cuestiones de orden individual o familiar, en general innatas vinculadas a la inteligencia, ecuación en la que tanto el sistema educativo, como el contexto socioeconómico, juegan a lo sumo, un papel secundario. Estas creencias resultaron exponerse con tal certeza, resultando para los docentes como obvias. La mayoría de las maestras, especialmente aquellas que sostuvieron opiniones más conservadoras, negaron que, en estos contextos, su práctica concreta pudiera impactar de manera alguna en el desempeño escolar de los alumnos.

\section{CONSIDERACIONES FINALES}

El maestro juega un papel central en el proceso de escolarización de los niños. Es un actor con un alto grado de reconocimiento y legitimación institucional. Sus ideas, creencias y expectativas lejos de ser inocuas, tienen un fuerte impacto en la imagen que los niños construyen de sí mismos y de sus posibilidades. Es por este lugar privilegiado dentro de sistema educativo y del imaginario colectivo, que el estudio de la subjetividad docente, en particular el estudio de las representaciones que elaboran sobre las causas del fracaso escolar, resulta interesante y necesaria, fundamentalmente en contextos sociales y culturales desfavorables.

A partir de los resultados obtenidos, es posible afirmar que no existe, en la muestra analizada, una representación social homogénea de las causas del fracaso escolar. Así, entre las maestras entrevistadas existen explicaciones diversas respectos de la desigualdad en los logros educativos de alumnos provenientes de distintos contextos socioculturales.

Se entiende que los discursos más prevalentes, donde se responsabilizaa al niño o a su familia por el fracaso escolar, contribuyen a legitimar la idea de que la desigualdad educativa es inevitable. Entender el fracaso o el éxito escolar desde una mirada a histórica con énfasis en los aspectos individuales y no desde la desigualdad estructural de la sociedad, o desde los marcos institucionales que la refuerzan, despolitiza la discusión. El docente puede posicionarse como un actor que educa para reproducir o para transformar cierto arreglo social. La primera perspectiva, más conservadora, explica el éxito a partir de los méritos y responsabilidades individuales. Desde esta visión, el docente brinda las herramientas necesarias para que cada cual se resuelva, se adapte y ocupe el lugar correspondiente en la sociedad en función de sus logros. Por el contrario, el docente posicionado desde la segunda perspectiva, ofrece herramientas que permiten visibilizar situaciones sociales injustas y educa para el cambio. De manera complementaria, se constata la circulación de valoraciones morales negativas sobre las familias en condiciones de pobreza, que impregnan fuertemente los discursos de muchas de las entrevistadas, y terminan por reforzar la idea de una herencia familiar que justifica el fracaso escolar. 
En las últimas décadas niños, niñas y adolescentes han sido reconocidos como sujetos de derechos (ONU, 1989). Sin embargo, en la actividad cotidiana de algunas instituciones vinculadas a la atención de la niñez y la adolescencia, parecieran resistir vestigios de una concepción que los posiciona como objetos de compasión y/o represión, en concordancia con el antiguo paradigma de la situación irregular. En este sentido, resulta importante señalar que al analizar el contenido de las entrevistas realizadas se encontraron profusas referencias al modelo tutelar, a partir del cual el énfasis se ubica en lo que le falta al niño o al adolescente para interactuar de forma adecuada en el mundo adulto.

Resulta importante señalar que las construcciones referidas en este trabajo, emergen en un contexto socio-histórico particular y en el marco de determinada institución, en este caso la educativa. Por lo tanto, resulta importante descentrar la discusión de la responsabilidad particular de cada docente sobre las trayectorias escolares de los alumnos, ya que sus creencias en relación a las acusas del fracaso escolar son, en parte, producto de prácticas institucionales; estas representaciones no son elecciones individuales de los docentes, sino que son conformaciones discursivas dependientes del contexto y circulan según lógicas complejas de reproducción y resistencias; en este sentido los maestros incorporan y resignifican las creencias y las ideas que circulan en la sociedad donde pertenecen. El docente porta estas elaboraciones, que operan como mecanismos de diferenciación, que al ser en parte inconscientes, reproduce más allá de su voluntad. Asimismo, es claro que las representaciones identificadas en el ámbito educativo sobre el tema en cuestión, constituyen uno de los múltiples aspectos a considerar en relación a la distribución desigual de los logros educativos.

Aun así, se considera que el maestro puede generar otros significados, otras lecturas respecto del fracaso escolar en contextos vulnerables, que ubiquen la responsabilidad no ya en el niño o en la familia, sino en las desigualdades que caracterizan la sociedad y en la organización del sistema educativo. Puede además posicionarse como un factor de resistencia, para quien el origen social del alumno, no funcione como el molde de sus expectativas. Se cree que la identificación de estas representaciones y la concientización por parte de los docentes de su existencia, contenido y efectos, permite adoptar una posición crítica y revisar estas creencias colectivas, no para necesariamente condenarlas y abandonarlas, pero si para problematizarlas y, eventualmente, matizarlas. Las representaciones sociales juegan un rol específico tanto en la interpretación de la realidad como en su producción, por lo que este estudio contribuye en parte, a la discusión de los potenciales efectos simbólicos que las construcciones elaboradas por los docentes tienen sobre las trayectorias educativas de los alumnos.

Con este trabajo se intenta además, aportar insumos para el análisis del tratamiento de las diferencias en el ámbito educativo y para la interpretación del problema de la desigualdad educativa desde un arco de sentidos más amplio. La complejidad del tema en cuestión y el acercamiento limitado planteado en este estudio, demandan el desarrollo de otras investigaciones a partir de marcos conceptuales tensionados en otros sentidos y de propuestas metodológicas diferentes. 


\section{REFERENCIAS}

Affonso, M. A., Collares, C. y Untoiglich, G. (2013). La maquinaria medicalizadora y patologizadora en la infancia. En G. Untoiglich. En la infancia los diagnósticos se escriben con lápiz. La patologización de las diferencias en la clínica y la educación (pp. 25-44). Buenos Aires: Noveduc.

Banchs, M. (2000). Aproximaciones procesuales y estructurales al estudio de las representaciones sociales. Papers on Social Representations, 9, 3.1-3.15. Recuperado de http://www.psr.jku.at/PSR2000/9_3Banch.pdF

Bourdieu, P. (2005). Capital cultural, escuela y espacio social. Buenos Aires: Siglo XXI.

Cáceres, P. (2003). Análisis cualitativo de contenido: una alternativa metodológica alcanzable. Psicoperspectivas, 2, 53-82. Recuperado de https://www.psicoperspectivas.cl/ index.php/psicoperspectivas/article/viewFile/3/1003

Castorina, J. A. y Kaplan, C. V. (1997). Representaciones sociales y trayectorias educativas. Una relación problemática. Educação \& Realidade, 22(2), 186-202. Recuperado de https://seer.ufrgs.br/educacaoerealidade/issue/viewIssue/3030/366

Consejo de Educación Inicial y Primaria. ATD. (2012). Informes y resoluciones de la ATD nacional ordinaria. "Maestra Mabel Basaistegui". [Online]. Recuperado de http:// www.cep.edu.uy/documentos/2012/atd/RESOLUCIONES_ATD_NACIONAL_JUNIO_2012.pdf

Consejo de Educación Inicial y Primaria. ATD. (2011). Informes y Resoluciones de la ATD nacional ordinaria. [Online]. Recuperado de http://www.cep.edu.uy/documentos/carpetaarchivos/atd/documentos/2011/ATD_Nacional_Agost o_11.pdf

Cuevas, Y. (2016). Recomendaciones para el estudio de representaciones sociales en investigación educativa. Cultura y representaciones sociales, 11(21), 109-140. Disponible en http://www.culturayrs.unam.mx/index.php/CRS/article/view/333

Escudero, J. M. (2005). Fracaso escolar, exclusión social: ¿De qué se excluye y cómo? Profesorado. Revista de Currículum y Formación de Profesorado, 9(1). Disponible en https:// recyt.fecyt.es/index.php/profesorado/article/view/42394

Garnique-Castro, F. y Gutiérrez-Vidrio, S. (2012). Educación básica e inclusión: un estudio de representaciones sociales. Magis, Revista Internacional de Investigación en Educación, 4(9), 577-593. https://doi.org/10.11144/Javeriana.m4-9.ebie

Gould, S. J. (2003). La falsa medida del hombre. Barcelona: Crítica.

Jodelet, D. (2011). Aportes del enfoque de las representaciones sociales al campo de la educación. Espacios en Blanco. Revista de Educación, 21, 133-154. Disponible en http:// www.espaciosenblanco.unicen.edu.ar/pdf/numerorosanterior/Revista_Espacios_en_ Blanco_N21.pdf

Kachinovsky, A. y Gabbiani, B. (Coords.). (2014). Una alternativa al fracaso escolar. Hablemos de buenas prácticas. Montevideo: Ediciones Universitarias/Comisión Sectorial de Investigación Científica/Universidad de la República. 
Kaplan, C. (2013). La inteligencia escolarizada. Representaciones sociales de los maestros sobre la inteligencia de los alumnos y su eficacia simbólica. Buenos Aires: Miño y Dávila.

Kaplan, C. (2005). Desigualdad, fracaso, exclusión: ¿cuestión de genes o de oportunidades? En C. Kaplan y S. Llomovatte (Coords.). Desigualdad educativa: la naturaleza como pretexto (pp. 75-98). Buenos Aires: Noveduc.

Kreimer, R. (2001). Historia del mérito. [Online]. Recuperado de https://www.academia. edu/3738487/Historia_del_m\%C3\%A9rito_libro_

Lewontin, R., Steven, R. y Kamin, L. (2003). No está en los genes: racismo, genética e ideología. Barcelona: Crítica.

López, A. S. (2010). Relación familia escuela en contextos de pobreza. Posibilidades y limitaciones en los procesos educativos. CUHSO $\cdot$ Cultura-Hombre-Sociedad, 20(1), 81-93. http://dx.doi.org/10.7770/cuhso-V20N1-art322

López, N. (2005). Equidad educativa y desigualdad social: desafíos de la educación en el nuevo escenario latinoamericano. Buenos Aires: IIPE-UNESCO. Disponible en https://unesdoc.unesco.org/ark:/48223/pf0000142599

López-Calva, L. y Lustig, N. (eds.). (2010). Declining Inequality in Latin America: A Decade of Progress? Washington D.C./Nueva York: Brookings Institution Press/United Nations Development Programme.

Marchesi, A. y Pérez, E. M. (2003). La comprensión del fracaso escolar. En Marchesi, A y Hernández Gil, C (coords.) El fracaso escolar. Una perspectiva internacional. Madrid: Alianza.

Martinis, P. y Falkin, C. (2017). Aspectos pedagógicos y de política educativa involucrados en los procesos de universalización del derecho a la educación. En A. Cristóforo, P. Martinis, M. N. Míguez y N. Viscardi (Coords.). Derecho a la educación y mandato de obligatoriedad en la Enseñanza Media. La igualdad en cuestión (pp. 35-100). Montevideo: Comisión Sectorial de Investigación Científica/Universidad de la República.

Moscovici, S. (1979). El psicoanálisis, su imagen y su público. Buenos Aires: Huemul.

Ochoa, M. y Orbeta, C. (2017). Discursos sobre clase social y meritocracia de escolares vulnerables en Chile. Cadernos de Pesquisa, 47(164), 496-518. https://doi. org/10.1590/198053143752

ONU. (20 de Noviembre de 1989). Convención sobre los Derechos del Niño. [Online]. Recuperado de https://www.un.org/es/events/childrenday/pdf/derechos.pdf

ONU. (junio, 2017). Observaciones del Comité de los Derechos del Niño sobre los informes periódicos presentados por Uruguay. 2007 y 2015. [Online]. Disponible en https:// www.bibliotecaunicef.uy/doc_num.php?explnum_id=174

Pérez, G. (1994). Investigación cualitativa. Retos, interrogantes y métodos. Madrid: La Muralla.

Piaget, J. (1999). La psicología de la inteligencia. Barcelona: Crítica. 
Rodelo, M. \& Castro, S. (2016). Reflexiones sobre la educabilidad: elemento fundamental en el proceso educacional del desarrollo humano. Cultura Educación y Sociedad, 7(2), 94-104. Disponible en https://revistascientificas.cuc.edu.co/culturaeducacionysocie$\mathrm{dad} /$ article/view/1104

Sandoval, C. (2002). Investigación cualitativa. Bogotá, D.C.: Instituto colombiano para el fomento de la educación superior, ICFES/Composición electrónica, ARFO. Recuperado de https:/panel.inkuba.com/sites/2/archivos/manual\%20colombia\%20cualitativo.pdf

Santos, É. (2019). A educação como direito social e a escola como espaço protetivo de direitos: uma análise à luz da legislação educacional brasileira. Educação e Pesquisa, 45. https://doi.org/10.1590/s1678-4634201945184961

Serrano, J. y Benzaquén, I. (2017). La frontera de posibilidades de desigualdad en América Latina. El trimestre económico, 84(334), 427-461. https://doi.org/10.20430/ete. v84i334.307

Wood, P. y Smith, J. (2018). Investigar en educación. Conceptos básicos y metodología para desarrollar proyectos de investigación. Madrid: Narcea.

Yin, R. K. (2009). Case study research. Design and methods (4 Ed.). London: SAGE.

República Oriental del Uruguay. ANEP. (mayo, 2019). Monitor educativo de enseñanza primaria. Estado de situación 2018. : División de Investigación, Evaluación y Estadística. Departamento de Investigación y Estadística Educativa. CEIP-Departamento de Estadística Educativa. Recuperado de http://www.anep.edu.uy/monitorRepo/Presentaciones\%20PDF\%20y\%20documentos/Estado\%20de\%20Situacion\%202018.pdf

República Oriental del Uruguay. Instituto Nacional de Estadística. (abril, 2018). Estimación de la pobreza por el método del ingreso. Año 2017. [Online]. Disponible en http:// www.ine.gub.uy/documents/10181/364159/Estimaci\%C3\%B3n+de+la+pobreza+por+e 1+M\%C3\%A9todo+del+Ingreso+2017/f990baaf-1c32-44c5-beda-59a20dd8325c

República Oriental del Uruguay. Parlamento Nacional. (12 de Diciembre de 2008). Ley General de Educación. [Ley $N^{o}$ 18.437]. Diario oficial de la República Oriental del Uruguay: No 27654. Recuperado de https://www.ineed.edu.uy/images/pdf/-18437-leygeneral-de-educacion.pdf

Mariana Diez Elola es Magíster en Derechos de Infancia y Políticas Públicas de la Universidad de República (Uruguay). Licenciada en Psicomotricidad de la Universidad de la República. Licenciatura en Psicomotricidad de la Escuela Universitaria de Tecnología Médica (EUTM). https://orcid.org/0000-0002-8995-8172 